\title{
Stereoselective synthesis of three-membered ring compounds via ylide routes
}

\author{
Li-Xin Dait, Xue-Long Hou and Yong-Gui Zhou \\ Laboratory of Organometallic Chemistry, Shanghai Institute of Organic Chemistry, \\ Chinese Academy of Sciences, Fenglin Lu, Shanghai 200032, China
}

\begin{abstract}
Three types of small ring compounds (epoxides, aziridines and cyclopropanes) can be synthesized stereoselectively via ylide route. Among them, the stereochemistry of vinyloxiranes, vinylaziridines, cyclopropylesters, amides and ketones can be tuned by the choice of reaction conditions and ylides with varying heteroatoms and ligands. Optically active epoxides and acetylenylaziridines can be prepared via camphor-derived chiral sulfonium ylide routes.
\end{abstract}

\section{INTRODUCTION}

Notwithstanding the fact that the appearance of the first phosphonium ylide may be traced back to one hundred years ago, the term ylide was introduced by George Wittig in 1944 [1a]. The recognition of these structurally interesting compounds as synthetically useful reagents was pronounced after the birth of the Wittig reaction in 1953 [1b]. Since then, the chemistry of ylides flourished rapidly and they have now become powerful and versatile synthetic tools [2] in the arsenal of organic chemistry.

An ylide can be viewed as a special carbanion which bears a neighboring positively charged heteroatom. Ylides can undergo three types of reactions: olefination, cyclization to three-membered ring (epoxidation, aziridination, and cyclopropanation), and rearrangement reaction. The reaction of ylides with an electrophilic carbon atom of a $\mathrm{C}=\mathrm{X}(\mathrm{X}=\mathrm{O}, \mathrm{C}, \mathrm{N})$ bond (carbonyl compound, Michael acceptor or imine) gives a betaine or oxetane intermediate. From this intermediate, elimination of the heteroatomcontaining group can occur in either one of two different modes resulting in cyclization or olefination. From this point, the use of an ylide is an alternative approach to that of the widely used carbene or carbanion route in synthesizing these small-ring compounds. Among all kinds of ylides, the phosphonium ylide was mainly used in olefination [1a,2], and the cyclization reactions are mainly carried out with S, As, or Te ylides [1a,2]. A number of papers on ylide epoxidation and cyclopropanation have been published, but stereochernical control of the reaction products still remains as a challenging problem. In sharp contrast to ylide epoxidation and cyclopropanation, the ylide aziridination reaction is rather undeveloped. Considering the importance of the small-ring compounds [3] in organic synthesis, which have notable biological significance [4] and can undergo various chemical transformations, and in conjunction with our experience of ylide chemistry [2] and transformations [5] of small-ring compounds, we decided to explore the stereocontrolled and/or asymmetric synthesis of three-membered ring compounds (Scheme 1) via the ylide cyclization route. In this paper, we would like to summarize our findings on this facet.

\section{EPOXIDATION VIA SULFONIUM YLIDE ROUTE}

Epoxides are versatile intermediates in organic chemistry, the electrophilic or nucleophilic ring opening reaction of them leads to 1,2-difunctionalized systems or to the formation of a new $\mathrm{C}-\mathrm{C}$ bond [6]. The

*Lecture presented at the 5th International Conference on Heteroatom Chemistry (ICHAC-5), London, Ontario,

Canada, 5-10 July 1998, pp. 369-512.

$\dagger$ Corresponding author. 


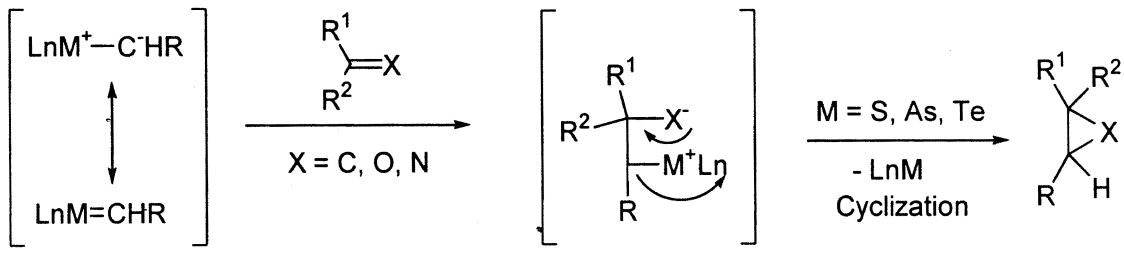

\section{Scheme 1}

ylide $\mathrm{LnM}^{+} \mathrm{CH}^{-} \mathrm{R}$ route is a convenient and attractive method because ylides are generally easily prepared and MLn can be recovered and reused.

Among various functionalized oxiranes, vinyloxirane has been shown to be one of the most important synthetic intermediates [3,7]. Because of the known [2,3]- $\sigma$-rearrangement, allylic sulfonium ylides have found limited application in the preparation of vinyloxiranes. The successful use of a nonrearrangeable 3trimethylsilylated dimethylsulfonium allylide, generated by the deprotonation of corresponding sulfonium salts, in the preparation of vinylaziridines [8] encouraged us to use the sulfonium salt as an ylide precursor in the preparation of vinyloxiranes.

Under extremely mild conditions, aldehydes reacted smoothly with a silylated dimethylsulfonium allylide, produced in situ from the corresponding dimethylsulfonium salt by solid $\mathrm{KOH}$ in acetonitrile, to furnish the trans epoxide as the major product in excellent yield (eqn 1, Scheme 2). In the presence of $\mathrm{LiBr}$, the aldehyde reacted with a preformed ylide, generated in situ from the diphenylsulfonium salt and $\mathrm{KN}\left(\mathrm{SiMe}_{3}\right)_{2}$ in THF at low temperature, to afford the epoxide in excellent yields and with very high cis selectivity (eqn 2, Scheme 2) [9].

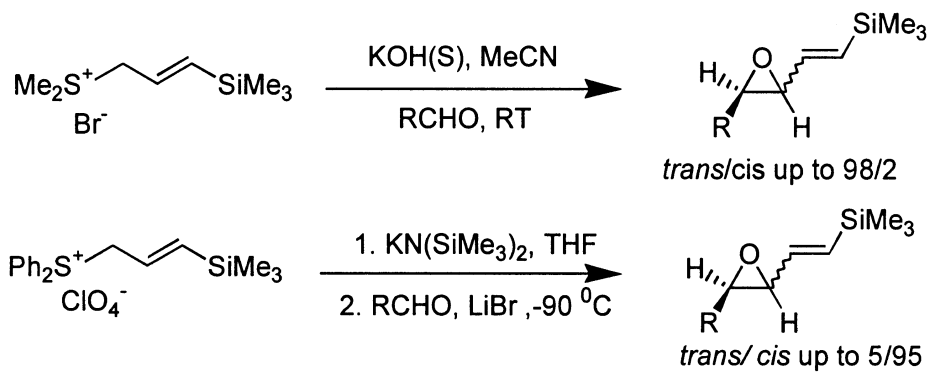

\section{Scheme 2}

The reactions shown in eqns 1 and 2 provide high stereoselectivity for the preparation of either trans or cis-trimethylsilylvinyloxiranes in excellent yields. To our knowledge, both stereoisomers of vinyloxiranes have not been obtained using the same ylide type. In addition, epoxidation with sulfonium ylides has never been found to give preferentially the cis-isomers. It should be pointed out that the addition of $\mathrm{LiBr}$ in the low temperature reaction (eqn 2) is crucial. Otherwise, an epoxide with a ratio of trans: cis $=2: 1$ would be obtained.

The possible intermediates in achieving either trans or cis-epoxides under different conditions might be postulated as shown in Scheme 3. On using the dimethylsulfonium salt under phase-transfer conditions, the reaction proceeded via intermediate $\mathbf{A}$ to furnish the thermodynamically stable trans epoxides. With the diphenylsulfonium salt, the lithium salt changed the reaction path by coordination with both the substrate and ylide through a halogen bridge. The reaction proceeded via the more favorable transition state $\mathbf{B}$ to give an unstable intermediate $\mathbf{C}$ followed by an immediate antielimination of $\mathrm{Ph}_{2} \mathrm{~S}$ to furnish cis-epoxides.

The ylide route is also an alternative approach [3] to prepare optically active epoxides. From the same starting material D-(+)-camphor, chiral sulfides in which the sulfur atom was situated outside the ring and oriented at the exo or endo position (Scheme 4) were prepared and used in one-pot asymmetric ylide epoxidations. Epoxides with opposite asymmetric induction were obtained using either exo or endo sulfides. When benzyl sulfides were used for asymmetric benzylidene transfer, a stoichiometric 


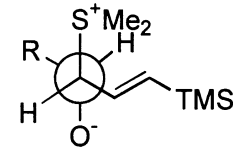

Intermediate A

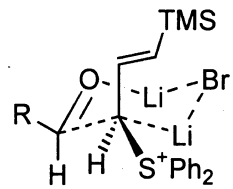

Transition state $\mathbf{B}$

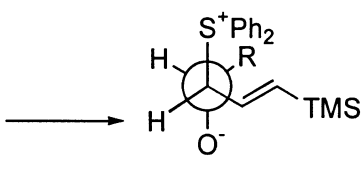

Intermediate C

\section{Scheme 3}

epoxidation was realized with high ee values and the trans isomers were obtained exclusively. A catalytic version of this reaction was achieved by employing methyl sulfides and high yields and enantioselectivities were obtained [10].
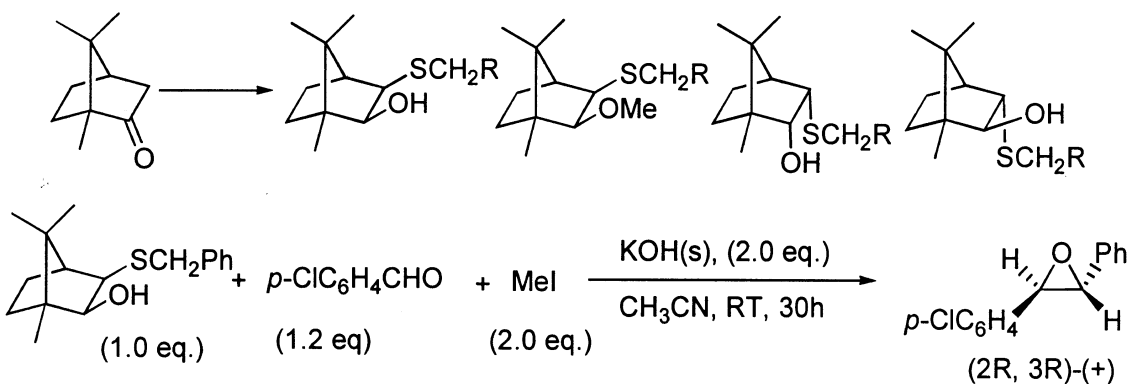

Stoichiometric Asymmetric epoxidation Yield: $96 \%$; ee: $77 \%$

Catalytic Asymmetric epoxidation Yield: $93 \%$; ee: $60 \%$

\section{Scheme 4}

Using a similar method, optically active 2,3-epoxyamides [11] can be also synthesized via the sulfonium ylide route (eqn 3 , Scheme 5). The absolute configuration $(2 \mathrm{R}, 3 \mathrm{~S}$ ) of the reaction product is determined by chemical transformations.

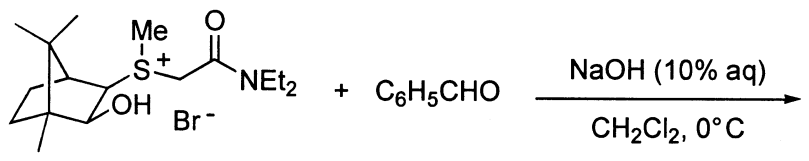<smiles>CCOC[C@@H]1O[C@H]1[PH2+]</smiles>

(2R, 3S)-(-)

Yield: $93 \%$; ee: $66.4 \%$

\section{Scheme 5}

\section{AZIRIDINATION VIA YLIDE ROUTE}

The fact that azirdination via an ylide route has not been extensively explored may be rationalized by the relatively low reactivity of common $N$-alkyl and $N$-arylimines toward nucleophilic attack as compared to that of carbonyl compounds (for epoxidation) and $\alpha, \beta$-unsaturated compounds (for cyclopropanation). The low reactivity of an ordinary imine can be enhanced by either introducing an electron-withdrawing group on the $\mathrm{N}$-atom or by using a Lewis acid to activate the $\mathrm{C}=\mathrm{N}$ bond (Scheme 6).

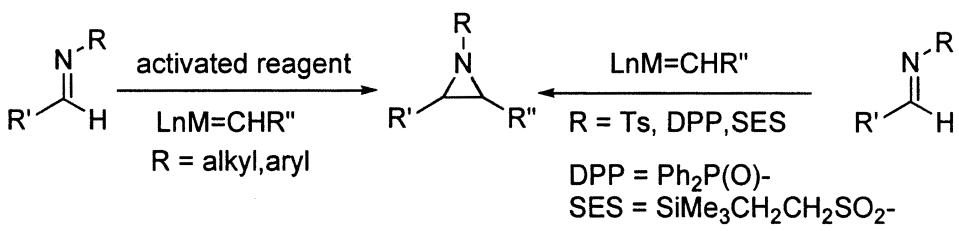

Scheme 6 
Semiempirical AMI calculations indicated that the qualitative order of electrophlicity is $\mathrm{PliCH}=\mathrm{NTs}>$ $\mathrm{PhCH}=\mathrm{NDPP}>\mathrm{PhCHO}>>\mathrm{PhCH}=\mathrm{NPh}$ [8]. Fortunately, activated N-tosylimines can smoothly react with all kinds of semistablized sulfonium ylides (eqn 4, Scheme 7) under solid-liquid conditions $[8,12]$. The same reaction proceeds with As and Te allylides under low temperature, but the yields are poor. A catalytic aziridination (eqn 5, Scheme 7) is also realized by employing a catalytic amount of $\mathrm{Me}_{2} \mathrm{~S}$ under solid-liquid phase transfer conditions [13].

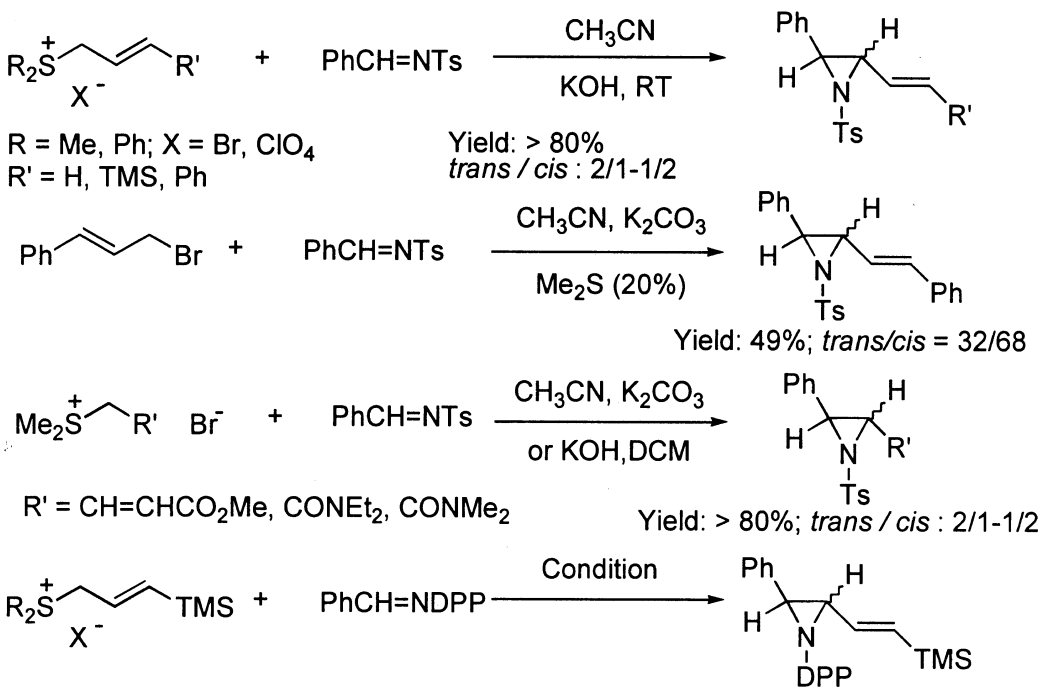

Condition A: NaH, DCM, RT; X = Br, R = Me; Yield: 92\%; trans $/$ cis $=10 / 90$ Condition B: NaHMDS/LiBr; $\mathrm{X}=\mathrm{ClO}_{4} ; \mathrm{R}=\mathrm{Ph}$; Yield: $93 \%$; trans $/$ cis $=91 / 9$

\section{Scheme 7}

Stabilized sulfonium ylides can also react with $\mathrm{N}$-tosylimines to afford the corresponding aziridines [14] (eqn 6, Scheme 7) in high yields and poor trans/cis selectivity. Either trans or cis- $N$ phosphinoylvinylaziridines can be synthesized (eqn 7, Scheme 7) by the reaction of imines with the corresponding allylides at low temperature or at room temperature in high yields and good to excellent selectivities [15]. In all of the above reactions, a mixture of trans/cis isomers was obtained. After numerous investigations, exclusive $\mathrm{cis}$ selectivity was achieved by the reaction of $N$-sulfonylimines with propargylic ylides under phase-transfer conditions (eqn 8, Scheme 8) [16].

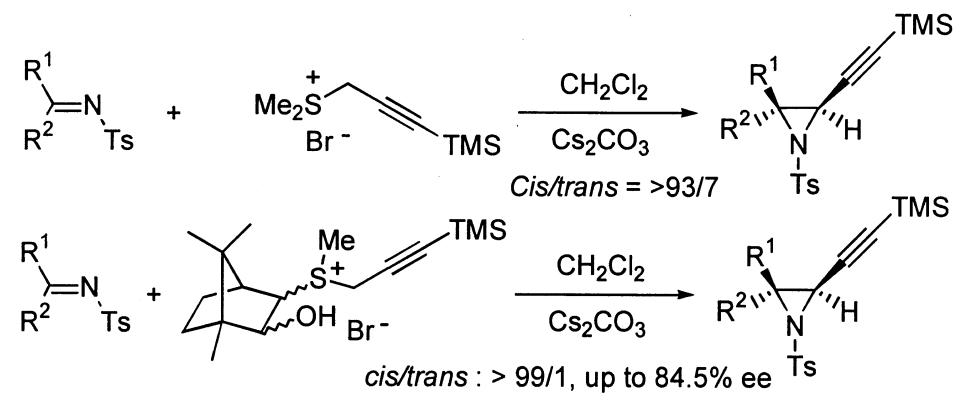

\section{Scheme 8}

The high stereoselectivity enables us to realize a reagent-controlled asymmetric aziridination by an ylide route. Chiral sulfonium salts were synthesized by the reaction of camphor-derived chiral sulfides with 3-bromo-l-trimethylsilylpropyne. Under solid-liquid phase transfer conditions, optically active acetylenylaziridines were obtained in high yields and moderate to good ee values (eqn 9, Scheme 8). Opposite asymmetric induction was achieved with sulfonium salts containing exo and endo-sulfido groups. The absolute configuration was determined by chemical transformations. The exclusive cis 
selectivity may be explained by an intermediate formed by [2+2] cycloaddition between the imines and the ylides. [2+2] cycloaddition is the rate-determining step. Due to steric hindrance, only the trans intermediate was formed, then intramolecular trans elimination of dimethylsulfide to give cis aziridines. Another chiral, sulfide-catalyzed asymmetric ylide aziridination also appeared in 1996 [17], which gave high $e e$ values and proceeded in a catalytic mode, albeit it requires strict reaction conditions and suffers from low trans/cis selectivity $(\approx 3 / 1)$. The present asymmetric aziridination is a stoichiometric reaction but may represent a promising general and practical approach to optically active aziridines due to its compatibility with a wide range of substrates, high yields, and very mild reactions conditions. Furthermore the ylide precursors could be recovered in higher than $80 \%$ yields without loss of optical purity and could be resued.

The addition of carbenoids [18] or ylides to a $\mathrm{C}=\mathrm{N}$ double bond has been demonstrated as a synthetic strategy for aziridination in recent years. However, the ylide and carbenoids methodologies can only be applied to an activated imine, that is $\mathrm{C}=\mathrm{N}$ double bonds with an $N$-electron-withdrawing group, such as p-tolylsulfonyl (Ts) $[8,10,12,13,14,16]$, diphenylphosphinoyl (DPP) [15] or 2-(trimethylsilyl)ethylsulfonyl (SES) [17]. No report has appeared for the reaction of a nonactivated imine with a semistablized or stablized ylide. Considering the vigorous conditions required for the deprotection and the difficulties in the preparation of activated imines from certain carbonyl compounds, developing a general and facile method for the aziridination of common $N$-alkyl and $N$-aryl imines is a challenge.

Encouraged by the successful activation of imines by Lewis acids in allylation reactions [19] and aziridination [20] of $\mathrm{BF}_{3}{ }^{\circ} \mathrm{OEt}_{2}$ activated imines with ethyl diazoacetate, we examined the $\mathrm{BF}_{3}{ }^{\circ}, \mathrm{OEt}_{2}$ and TMSCl activation of imines in the ylide reaction for the preparation of vinyl-and ethynylaziridines (eqn 10, Scheme 9). A variety of aromatic aldimines, either $N$-aryl or $N$-alkyl, could be aziridinated with good to excellent yields, but aziridination failed when aliphatic aldimines were used as substrates. The stereoselctivity of the aziridination is strongly dependent on the nature of the group on the nitrogen atom of the imines: $N$-aryl aromatic aldimines gave purely the cis-aziridine, while $N$-alkyl aromatic aldimines gave a mixture of cis and trans aziridines.

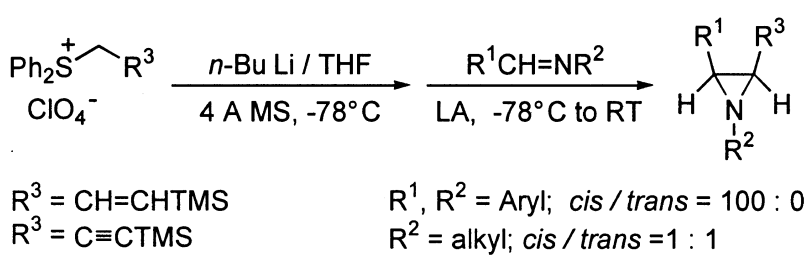

Scheme 9

\section{CYCLOPROPANATION VIA YLIDE ROUTE}

Vinylcyclopropanations are important compounds not only because they are versatile intermediates in organic transformations and in the total synthesis of complex molecules, but also they form the substructure of several biologically active natural compounds [3]. By retrosynthetic analysis, the addition of allylic ylides $\mathrm{LnM}^{+} \mathrm{CH}^{-} \mathrm{CH}=\mathrm{CHX}$ to Michael acceptors is a convenient and attractive method because the ylides are generally easily prepared and MLn can be recovered and reused. However, practical methods for the synthesis of vinylcyclopropanes via the allylide route remains undeveloped.

The allylic telluronium ylides, generated in situ from the corresponding telluronium salts in the presence of a lithium salt, reacted with $\alpha, \beta$-unsaturated esters or amides to afford trans-2-vinyl-trans3 substituted cyclopropyl esters or amides, respectively, with high selectivity and generally excellent yields. In the absence of lithium salts, the stereoselectivity of these reaction changed to give cis-2-vinyltrans-3-substituted cyclopropyl esters or amides (Scheme 10). The selectivity of the two isomers can be tuned from 99:1 to 1:99 [21].

The reaction mechanism might be postulated as shown in Scheme 10. We have qualitatively determined that the Michael addition is a rate-determining step. In light of the well-accepted mechanisly for ylide cyclopropanation [22], a possible mechanism for the reaction between the ylide and 


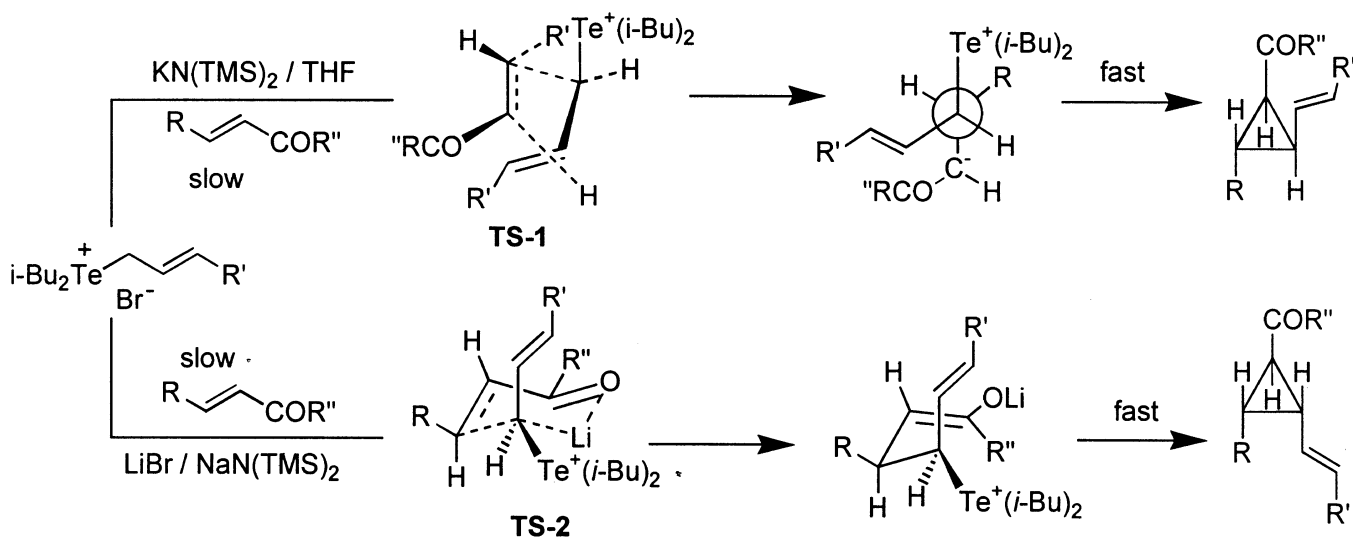

\section{Scheme 10}

the $\alpha, \beta$-unsaturated esters or amides using $\mathrm{KN}(\mathrm{TMS})_{2}$ as the base is depicted in Scheme 10. The reaction proceeded via a stable transition state 1 (TS-1) to give the product. While in the presence of $\mathrm{LiBr}$, the coordination of lithium salt might be an important factor. It has been demonstrated by Vedejs \& Schmidbauer [23] that some Lewis acids, such as $\mathrm{MgBr}_{2}$ and $\mathrm{LiX}$, can coordinate with $\mathrm{R}_{3} \mathrm{P}=\mathrm{CH}_{2}$. Recently, Armstrong [24] reported the structure of a single crystal of $\left[\mathrm{Ph}_{2} \mathrm{P}=\mathrm{CH}_{2}-\mathrm{LiN}(\mathrm{Bn})_{2}\right]_{2}$ showing the coordination of methylene phosphorane with lithium, and proposed that other heteroatom ylides might also be potential Lewis base donors to alkali metal cations. Similarly, we think the lithium ion can coordinate with both the ylidic carbon and the carbonyl oxygen of the esters or amides to form a sixmembered ring transition state (TS-2), which disposed $\mathrm{Te}(i-\mathrm{Bu})_{2}$ in a equatorial orientation due to steric hindrance. A fast anti-elimination would give the corresponding product.

Contrary to the results obtained in the reaction of ylides with $\alpha, \beta$-unsaturated esters or amides, we found that by altering the base in the preparation of the ylide, the tuning of the stereochemistry failed in the cyclopropanation reaction with $\alpha, \beta$-unsaturated ketones. But by choosing different types of ylides, we were able to tune the stereochemistry of the cyclopropanation reaction of $\alpha, \beta$-unsaturated ketones. The semistablized telluronium ylides reacted with $\alpha, \beta$-unsaturated ketones to afford cis-2-vinyl-trans3 substituted cyclopropyl ketones (eqn 11, Scheme 11) with high stereoselectivity and in high to excellent yields [25]. Conversely, these enones gave trans-2-vinyl-trans-3-substituted cyclopropyl ketones (eqn 12, Scheme 11), when the corresponding arsonium ylides were employed.

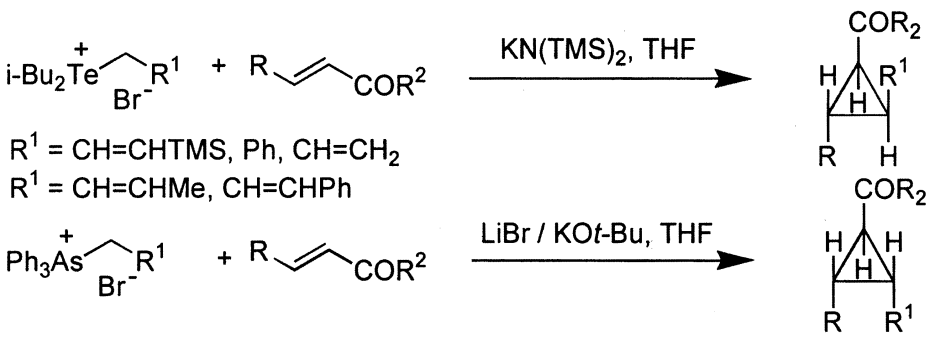

\section{Scheme 11}

Highly electron-deficient vinyl and ethynylcyclopropane 1,1-dicarboxylic esters were conveniently synthesized (eqn 13, Scheme 12) by the reaction of allylic diisobutyltelluronium ylides with alkylidene or arylmethylidene malonic esters with high yields and high stereoselectivity [26].

\section{CONCLUSION}

The stereocontrolled methods described in this paper provide some facile and general means for the synthesis of small-ring compounds. A salient feature is that the stereochemistry of the resulting small ring compounds (epoxides, aziridines, and cyclopropanes) can be tuned at will by proper choice of reaction 


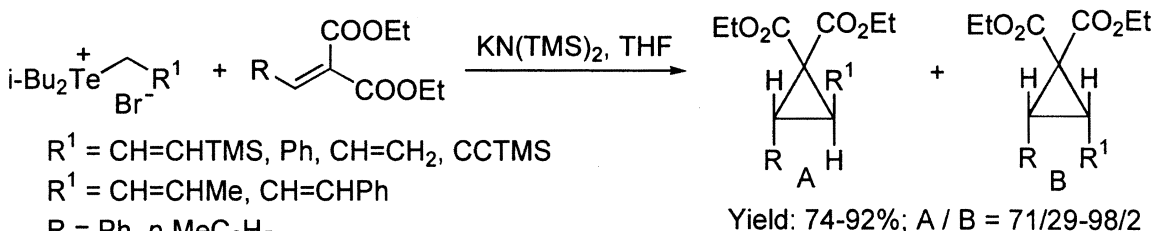

$\mathrm{R}=\mathrm{Ph}, \mathrm{p}-\mathrm{MeC}_{6} \mathrm{H}_{5}$

Yield: $74-92 \% ; A / B=71 / 29-98 / 2$

Scheme 12

conditions and ylides. In addition, optically active epoxides and aziridines can also be synthesized by using camphor-derived chiral ylides. The role of the lithium salt and different type of ylides in the ylide epoxidation and cyclopropanation is noteworthy. These features, together with the generality of these methods and easy preparation of ylides, make these reactions valuable tools for organic synthesis.

\section{ACKNOWLEDGEMENTS}

Financial support from the National Natural Science Foundation of China (29790127) and the Chinese Academy of Sciences are gratefully acknowledged. Many thanks are due to Dr An-Hu Li, Dr De-Kun Wang, Dr Yong Tang, Mr Xiao-Fang Yang, and Mr Wei-Ping Deng for their contributions to the research program of ylide cyclization.

\section{REFERENCES}

1 (a) A. W. Johnson. Ylid Chemistry. Academic Press, New York (1966). (b) G. Wittig, G. Geissler. Justus Liebigs Ann. Chem. 580, 44 (1953).

2 A.-H. Li, L.-X. Dai, V. K. Aggarwal. Chem. Rev. 97, 2341 (1997); A. Padawa, S. F. Hornbuckle. Chem. Rev. 91, 263 (1991); Y. Z. Huang, Y. Tang, Z. L. Zhou. Tetrahedron 54, 1667 (1998); O. Meyer, P. C. Cagle, K. Weikhardt, D. Vichard, J. A. Gladysz. Pure Appl. Chem. 68, 79 (1996).

3 T. Hudlicky, J. W. Reed. In Comprehensive Organic Synthesis (B. M. Trost, I. Fleming, eds), Vol. 5, pp. 899970, 971-997. Pergamon Press, Oxford, UK (1991), and references cited therein.

4 S. Danishefsky. Acc. Chem. Res. 12, 66 (1979). D. M. Jerina, J. M. Daly. Science 185, 573 (1974).

5 L.-X. Dai, B.-L. Lou, Y.-Z. Zhang, G.-Z. Gou. Tetrahedron Lett. 27, 4343 (1986); L.-X. Dai, B.-L. Lou, Y.-Z. Zhang. J. Am. Chem. Soc. 110, 5195 (1988).

6 J. Gorzynski Smith. Synthesis 629 (1984); A. S. Rao, S. K. Paknikar, J. G. Kirtane. Tetrahedron 39, 2367 (1983).

7 C. S. Stephenm. Chem. Eng. News 24, 24 (1994).

8 A.-H. Li, L.-X. Dai, X.-L. Hou. J. Org. Chem. 61, 4641 (1996).

9 Y.-G. Zhou, A.-H. Li, X.-L. Hou, L.-X. Dai. Chem. Commun. 1353 (1994).

10 A.-H. Li, L.-X. Dai, X.-L. Hou, Y.-Z. Huang, F.-W. Li. J. Org. Chem. 61, 489 (1996).

11 Y.-G. Zhou, X.-L. Hou, L.-X. Dai, L.-J. Xia, M.-H. Tang. J. Chem. Soc. Perkin Trans. I, in press.

12 A.-H. Li, L.-X. Dai, X.-L. Hou. Chem. Commun. 491 (1996).

13 A.-H. Li, L.-X. Dai, X.-L. Hou. J. Chem. Soc. Perkin Trans. I 867 (1996).

14 A.-H. Li, L.-X. Dai, X.-L. Hou. J. Chem. Soc. Perkin Trans. I 2725 (1996); Y.-G. Zhou, A.-H. Li, X.-L. Hou, L.-X. Dai. Tetrahedron Lett. 38, 7225 (1997).

15 X.-L. Hou, X.-F. Yang, L.-X. Dai, X.-F. Chen. Chem. Commun. 747 (1998).

16 A.-H. Li, Y.-G. Zhou, L.-X. Dai, X.-L. Hou, L.-J. Xia, L. Lin. Angew. Chem. Int. Eds. Engl. 34, 1317 (1997).

17 V.-K. Aggarwal, A. Thompson, R. V. H. Jones, M. C. H. Standen. J. Org. Chem. 61, 8368 (1996); for a corresponding epoxidation, see: V. K. Aggarwal, J. G. Ford, A. Thompson, R. V. H. Jones, M. C. H. Standen. J. Am. Chem. Soc. 118, 7004 (1996).

18 K. B. Hansen, N. S. Finney, E. N. Jacbosen. Angew. Chem. Int. Eds. Engl. 34, 676 (1995). Z. Zhu, J. H. Espenson. J. Org. Chem. 60, 7090 (1995).

19 G. E. Keek, E. J. Enholm. J. Org. Chem. 50, 146 (1985); D.-K. Wang, L.-X. Dai, X. L. Hou. Tetrahedron Lett. 36, 8649 (1995). 
20 L. Casarrubios, J. A. Perez, M. Brookhart, J. L. Templeton. J. Org. Chem. 61, 8358 (1996).

21 Y. Tang, Y. Z. Huang, L. X. Dai, Z. F. Chi, L. P. Shi. J. Org. Chem. 61, 5762 (1996).

22 Y. Z. Huang, Y. C. Shen. Adv. Organomet. Chem. 20 (1982); F. H. Greenberg, F. H. Schulman. J. Org. Chem. 58, 5853 (1993); B. M. Trost. J. Am. Chem. Soc. 89, 138 (1967).

23 H. Schmidbauer. Acc. Chem. Res. 8, 62 (1975); E. Vedejs, G. P. Meier, K. A. Snoble. J. Am. Chem. Soc. 103, 2823 (1981).

24 D. R. Armstrong, M. G. Davidson, D. Moncrief. Angew. Chem. Int. Eds Engl. 34, 478 (1995).

25 Y. Tang, Y. Z. Huang, L. X. Dai, J. Sun, W. Xia. J. Org. Chem. 62, 954 (1997).

26 Y. Tang, Z. F. Chi, Y. Z. Huang, L. X. Dai, Y. H. Yu. Tetrahedron 52, 8747 (1996). 